\title{
Laboratory evaluation of metal elements urease inhibitor and DMPP nitrification inhibitor on nitrogenous gas losses in selected rice soils
}

\begin{abstract}
Urea is considered as the most widely used nitrogen $(\mathrm{N})$ fertilizer. Unfortunately, its application is associated with losses such as emissions of ammonia (NH3) and nitrous oxide (N2O) in a gas form. In addition to the economic loss, such $\mathrm{N}$ losses may threaten atmospheric quality. Application of both urease and nitrification inhibitors is advocated as an approach to mitigate these gaseous losses. Thus, laboratory studies were carried out to evaluate the effects of urease inhibitor-coated urea, nitrification inhibitor-coated urea, and other modified urea fertilizers on $\mathrm{NH} 3$ volatilization and $\mathrm{N} 2 \mathrm{O}$ gas emissions in selected anaerobic rice soils. Copper $(\mathrm{Cu})$ and $\mathrm{Zinc}(\mathrm{Zn})$ were selected as urease inhibitors and DMPP (3,4-dimethylpyrazole phosphate) as nitrification inhibitor. Nitrogen fertilizer treatments used were urea, $\mathrm{Cu}$-coated urea $(\mathrm{CuU}), \mathrm{Zn}$-coated urea $(\mathrm{ZnU}), \mathrm{Cu}+\mathrm{Zn}$-coated urea $(\mathrm{CuZn})$, DMPP-coated urea (DMPPU), DMPP $+\mathrm{Cu}+\mathrm{Zn}$-coated urea (DMPPCuZn), OneBaja, sulfur-coated urea (SU), and dolomite-coated urea (DU). Results demonstrated that $\mathrm{CuU}$, ZnU, DMPPCuZn, SU, and OneBaja were effective in reducing NH3 volatilization by 12.12i $37.48 \%$ compared to urea, while DMPPU had no effect on NH3 volatilization. Meanwhile, sulfur-coated urea (SU), CuU, ZnU, CuZn, OneBaja, DMPPU, and DMPPCuZn reduced $\mathrm{N} 2 \mathrm{O}$ emission over urea by $14.86,17.57,21.62,29.73,29.73,33.78$, and $48.64 \%$, respectively. These results suggest that using $\mathrm{Cu}, \mathrm{Zn}$, or combinations of DMPP, $\mathrm{Cu}$, and $\mathrm{Zn}$ is recommended as an alternative to mitigate both $\mathrm{NH} 3$ volatilization and $\mathrm{N} 2 \mathrm{O}$ emission, in addition to providing positive impact to environment.
\end{abstract}

Keyword: Hydrolysis; Nitrification inhibitor; Urea; Urease inhibitors 